\title{
Coordinated development between agricultural economy and ecological environment in Huangshui River basin in Qinghai province
}

\author{
LiSheng-mei ${ }^{1-2, a} \quad$ Shi Pei-ji ${ }^{2, b}$ \\ ${ }^{1}$ College of Geography and Environmental Science, Northwest Normal University, Lanzhou, China \\ 730070 \\ ${ }^{2}$ Life and geography science institute, Qinghai Normal University, Xining, China 810008 \\ alishengmei1980@163.com \\ bshipj@nwnu.edu.cn
}

\begin{abstract}
Keywords: Huangshuiriver; agriculturale conomy; ecological environment; coordinated development
\end{abstract}

Abstract: Coordinated development of economy and environment is the key to sustainable development.In order to ensure that limited water resources maximum limit applied to production, life and ecological, this paperanalyzed the coordinated development between agricultural economy and ecological environmentby selecting the eight counties as the research object, andconstructed the agricultural economy development and ecological environment quality evaluation index system by usingentropy weight method. The results showed that agricultural development index and all the ecological environment quality index is low in HuangshuiRiver basin, among them agricultural economic index of Ledu county and agricultural economic index is higher than other counties ecological index, and the ecological environment quality in Haiyan county is bad, and in that area and Datong, Huangzhong county and Minhe County for the development ofshould focus on the protection of the ecological environment and improve. Ping'an County, Huangyuan county and Huzhu County agricultural economic index under the ecological environment index, agricultural economy development backward.

The rapid development of economic and social economic development and the shortage of resources, ecological environment deterioration of contradiction is more and more prominent, it is in this backdrop, implement the strategy of sustainable development economy and environment coordinated development is in urgent need of solving the problem of global strategy.Coordinated development is a systematic project involving economic, social, environmental and demographic sectors.Foreign ecological construction and economic coordinated development of the early start in the 1960s, the economist system method is applied to analyze correlation between ecological environment and economic development, improve the ecological environment of the research status of ${ }^{[1]}$.By the early 1990s, the development theory was proposed, which advocated the common development of social economy and ecosystem.In China, many scholars had done in-depth research, established the evaluation index system of the coordinated development of economy and environment ${ }^{[2-3]}$.Zhang li selectedShaanxi province, on the basis of analyzing the current situation of the development of regional economy and environment ${ }^{[4]}$. Because of water-lack in QinghaiHuangshui river basin, the ecological deterioration, natural vegetation withering, land desertification, salinization process is accelerated, underground water level drops, salinity increase, etc., have severely hindered the sustainable development of region, and affect the social economy 
and ecological environment coordinated development.In order to ensure that the limited water resources to maximum applied to production, life and ecology, we must coordinate the development of agricultural economy and ecological environment the situation.

\section{Research area overview and data source}

Qinghai province is located in the inland hinterland of northwest China, Tibet plateau northeast, $72.12 \times 10^{4} \mathrm{~km}^{2}$. The total area of agricultural land in Qinghai province is $4.35 \times 10^{7} \mathrm{hm}^{2}$, which is $60 \%$ of the total area of Qinghai province.It is mainly distributed in Yellow River basin, Huangshui river basin and Qaidam area.At the end of 2015, the total population of Huangshui river basin in Qinghai was 56.82 million, and the total area of the Huangshui river area was $1.06 \times 10^{5}$ million yuan. Among them, the value added value of the first industry was $2.05 \times 10^{4}$ billion yuan, an increase of 36 . $57 \%$.Overall haven't changed much in recent years, the agricultural production structure in Qinghai province (shown table 1), crop production and animal husbandry output value, basically unchanged, at 50\%, up and down and planting proportion declining gradually, gradually increase the proportion of animal husbandry.Forestry output value is small, heavy at $1 \%-5 \%$ or so;Fishery production value is the smallest, less than 0.5 percent.It shows that the agricultural structure is unreasonable and the agricultural ecosystem is single.Research data is from the 2016 statistical yearbook of Qinghai province and the statistical bulletin of Qinghai province.

\section{Coordinated development model introduction and index system construction}

\section{Model introducing}

The degree of coordination is the degree to which the system is in harmony with each other in the development process, and the trend of the system from disorder to order is of great significance to promote the coordinated development of both ${ }^{[5]}$.Expressed as equation (1),C indicates the coordination degree, and $\mathrm{K}$ coordinates the development adjustment coefficient:

$$
\begin{aligned}
& \mathrm{C}=\left[U_{1} * U_{2} *\left\{\frac{U_{1}+U_{2}}{2}\right\}^{-2}\right]^{K} \\
& U_{i}=\sum_{j=1}^{m} w_{i j} * u_{i j}
\end{aligned}
$$

$U_{i}$ is the index level of $I$ system, $w_{i j}$ is the index weight, and $u_{i j}$ is the coefficient of system efficiency.Coordination degree can reflect the degree of environmental and economic coordination, two system is unable to say at what level of coordination, a combination of coordination degree and coordination development degree, can reflect the environment and economy coordinated development level comprehensively, therefore, it is necessary to introduce the coordinated development degree model ${ }^{[6]}$ :

$$
\begin{array}{r}
\mathrm{T}=\mathrm{a} * U_{1}+b * U_{2} \\
\mathrm{D}=\sqrt{C * T}
\end{array}
$$

$\mathrm{T}$ in the form (3) represents the coordinated development coefficient, which reflects the level of coordination between the two systems. The value of $a$ and $b$ is 0.5.In formula (4); $\mathrm{D}$ for the coordinated development degree, coordination degree and the geometric mean of the coordinated development coefficient, can reflect the regional ecological environment quality changes and the synchronicity of agricultural economic development and the environmental and agricultural comprehensive level of economic development. 


\section{construction of the index system for the coordinated development of agricultural economy} and ecological environment in Huangshui river basin

In order to accurately reflect the level of coordinated development between the agricultural economy and the ecological environment, the index system is shown in table 1 according to the principle of hierarchy, independence and operability. The development of agricultural economy can be investigated through three aspects: agricultural base condition, agricultural economic benefit and utilization efficiency of agricultural resources. The agricultural basic conditions are mainly manifested in the various resources, land resources, labor resources, mechanized resources and technicians.The economic benefit of agriculture depends mainly on the farmers' income, agricultural production value and other factors. The quality of ecological environment can be studied from two aspects: macro ecological environment and agricultural ecological environment.The utilization of soil and water resources is a good way to investigate the ecological environment quality. In macro environment, forest cover and land desertification area two indexes reflect the utilization of land resources; In the agricultural environment, the environmental bearing capacity is reflected by the use of fertilizer, the use of plastic film and the non-hazardous disposal rate of feces ${ }^{[7-8]}$.

\section{Evaluation of the development of agricultural economy and the coordinated development of ecological environment}

\section{Data processing and results}

To eliminate the influence of different units in the index, the raw data is standardized to handle ${ }^{[9]}$, and then the index information entropy and the weight. The entropy $\mathrm{H}$ and weight $\mathrm{W}_{\mathrm{i}}$ of the index calculated respectively are as follows:

$$
\begin{gathered}
H_{i}=-k \sum_{j=1}^{n}\left(f_{i j} \operatorname{In} f_{i j}\right) \\
f_{i j}=\frac{r_{i j}^{\prime}}{\sum_{j=1}^{n} r_{i j}^{\prime}} \mathrm{k}=\frac{1}{\operatorname{Inn}}\left(\operatorname{supposing} f_{i j}=0, f_{i j} \operatorname{In} f_{i j}=0\right) \\
W_{i}=\frac{1-H_{i}}{m-\sum_{i=1}^{m} H_{i}}
\end{gathered}
$$

The entropy and weight are calculated and the results are shown in table 1 . It can be seen from the table above, within the agricultural economic system, $\mathrm{X}_{2}, \mathrm{X}_{5}, \mathrm{X}_{13}$ weight is higher, shows that increasing agricultural labor force and the area of the facilities of agricultural production and vigorously develop animal husbandry and increase its output value proportion to improve agricultural economic benefits, ecological environment system, the weight is higher $\mathrm{X}_{14}, \mathrm{X}_{15}, \mathrm{X}_{16}$, $\mathrm{X}_{18}$ index, forest coverage rate and to increase the amount of water resources allocation and reduce land desertification area will have a positive benefit on environmental quality. But the developmentof the agricultural economic system and the ecological environment quality is not harmonious factors, such as increasing amount of water resources allocation is bound to cause the excessive development of groundwater and ecological water thus diverted, lead to the deterioration of ecological environment quality; The use of fertilizer will increase the efficiency of agricultural production, but excessive use will cause serious pollution to soil and groundwater, resulting in the overall deterioration of ecological environment quality in the basin.

\section{agricultural economic development index and ecological environmental quality index}

From formula (2), we can see that the calculation of agricultural economic development index and ecological environment quality index needs to calculate its efficiency coefficient, and 
theefficiency coefficient can be calculated by

formula (9)- (10) calculation:

$$
\begin{aligned}
& u_{i j}=\frac{X_{i j}-\beta_{i j}}{\alpha_{i j}-\beta_{i j}} \\
& u_{i j}=\frac{X_{i j}-\beta_{i j}}{\alpha_{i j}-\beta_{i j}} \beta_{i j} \leq X_{i j} \leq \alpha_{i j}
\end{aligned}
$$

$0 \leq u_{i j} \leq 1, u_{i j}$ is the efficacy coefficient, the indicators reflect the positive effects of the formula

Tab.1 agricultural economy and environmental quality coordinated development index system of Qinghai

\begin{tabular}{|c|c|c|c|c|}
\hline The project layer & Factors layer & Index layer & $\begin{array}{l}\text { Serial } \\
\text { number }\end{array}$ & $\mathrm{W}_{\mathrm{i}}$ (weight) \\
\hline \multirow{13}{*}{$\begin{array}{c}\text { The agricultural } \\
\text { economic development } \\
\text { index }\end{array}$} & \multirow{5}{*}{$\begin{array}{l}\text { Agricultural base } \\
\text { condition }\end{array}$} & Total cultivated area $/ \mathrm{hm}^{2}$ & $\mathrm{X}_{1}$ & 0.0287 \\
\hline & & Agricultural labor force $/ 10^{4}$ person & $\mathrm{X}_{2}$ & 0.0391 \\
\hline & & Mechanical power /KW & $\mathrm{X}_{3}$ & 0.03 \\
\hline & & agrotechnologist /person & $\mathrm{X}_{4}$ & 0.0274 \\
\hline & & Facility agricultural production area $/ \mathrm{m}^{2}$ & $\mathrm{X}_{5}$ & 0.039 \\
\hline & \multirow[t]{4}{*}{ Resource efficiency } & Land restoration index $1 \%$ & $\mathrm{X}_{6}$ & 0.0287 \\
\hline & & Labor productivity /yuan.person $^{-1}$ & $\mathrm{X}_{7}$ & 0.0259 \\
\hline & & Unit area output value /yuan. $\mathrm{m}^{-2}$ & $\mathrm{X}_{8}$ & 0.0275 \\
\hline & & Effective irrigation area $/ \mathrm{m}^{2}$ & $\mathrm{X}_{9}$ & 0.025 \\
\hline & \multirow{4}{*}{$\begin{array}{c}\text { Agricultural economic } \\
\text { efficiency }\end{array}$} & Gross agricultural product $/ 10^{4}$ yuan & $\mathrm{X}_{10}$ & 0.0302 \\
\hline & & Per capita income of farmers /yuan & $\mathrm{X}_{11}$ & 0.0283 \\
\hline & & Proportion of grain crops $1 \%$ & $\mathrm{X}_{12}$ & 0.0142 \\
\hline & & Livestock production value $/ \%$ & $\mathrm{X}_{13}$ & 0.0347 \\
\hline \multirow{7}{*}{$\begin{array}{l}\text { Ecological } \\
\text { environmental quality } \\
\text { index }\end{array}$} & \multirow{7}{*}{$\begin{array}{c}\text { Basic condition of } \\
\text { ecological } \\
\text { environment }\end{array}$} & Forest coverage $1 \%$ & $\mathrm{X}_{14}$ & 0.046 \\
\hline & & Land desertification area $/ \mathrm{m}^{2}$ & $\mathrm{X}_{15}$ & 0.0423 \\
\hline & & Allocation of water resources $/ \mathrm{m}^{3}$ & $\mathrm{X}_{16}$ & 0.0388 \\
\hline & & rainfall $/ \mathrm{mm}$ & $X_{17}$ & 0.0253 \\
\hline & & Fertilizer use $/ \mathrm{kg}$ & $\mathrm{X}_{18}$ & 0.0296 \\
\hline & & Use of plastic film $/ \mathrm{kg}$ & $\mathrm{X}_{19}$ & 0.0275 \\
\hline & & Fecal free disposal rate $1 \%$ & $\mathrm{X}_{20}$ & 0.0189 \\
\hline
\end{tabular}
Huangshui river basin

(9), formula (10) is used to reflect negative effects. $X_{\mathrm{ij}}$ is the actual value of the index, the upper and lower limits of each index are the indices of $\alpha_{i j} \mathrm{ij}$ and $\beta_{i j}$, and the lower limit interval is determined by the change of the extremum of the index in the interval.In the study, the extreme value should be adjusted to enlarge or reduce the extreme value by $1 \%$ to avoid the effect coefficient of the index.The efficiency coefficient matrix is calculated by formula (9) (10).According to the above model, a formula (1), (2), (3), (4) calculated from the following as a result, as shown in figure1. QinghaiHuangshui watershed overall agricultural economic development index are higher than the ecological environment, QinghaiHuangshui basin agricultural economic development and ecological environmental bearing capacity is not synchronized, the indexes showed that the main reason is to promote efficient development of facilities agriculture step by step, the other is the rapid development of animal husbandry, and the government to vigorously develop animal husbandry in all kinds of preferential policies are inseparable. 


\section{Analysis on the coordinated development of agricultural economy and ecological environment in shiyang river basin}

It needs a judgment standard to make certain what level of agricultural economyand theanalysis of the coordinated development of the agricultural ecological environment coordinated development between economic system and ecological environment system Huangshui river basin in Qinghai status. Coordination level refers to the coordination degree is divided into continuous interval, interval level represents a coordination degree, an interval represent a state of coordination, into a continuous coordinateladder(shown in table 3 ).

Tab.2 Coordination level criteria

\begin{tabular}{ccc|ccc}
\hline $\begin{array}{c}\text { sequence } \\
\text { number }\end{array}$ & value of D & Coordination level & $\begin{array}{c}\text { sequence } \\
\text { number }\end{array}$ & value of D & Coordination level \\
\hline 1 & $0-0.09$ & Extreme incongruity & 6 & $0.50-0.59$ & Barely coordination \\
2 & $0.10-0.19$ & Severe incongruity & 7 & $0.60-0.69$ & Primary coordination \\
3 & $0.20-0.29$ & Severe incongruity & 8 & $0.70-0.79$ & Moderate coordination \\
4 & $0.30-0.39$ & Minor incongruity & 9 & $0.80-0.89$ & Good coordination \\
5 & $0.40-0.49$ & upcoming incongruity & 10 & $0.90-1.00$ & Extreme coordination \\
\hline
\end{tabular}

Comparing table 3 and the data obtained from the calculation, the coordination degree, coordination level and coordinated development degree of agricultural system and ecosystem in the basinresearch area were obtained (table 4).

Tab.3 coordination degree, coordination degree and coordinated development of agricultural system and ecosystem in Huangshui watershed research area of Qinghai province

\begin{tabular}{ccccccccc}
\hline $\begin{array}{c}\text { Evaluation } \\
\text { index }\end{array}$ & $\begin{array}{c}\text { Ledu } \\
\text { county }\end{array}$ & $\begin{array}{c}\text { Ping'an } \\
\text { county }\end{array}$ & $\begin{array}{c}\text { Huzhu } \\
\text { county }\end{array}$ & $\begin{array}{c}\text { Minhe } \\
\text { county }\end{array}$ & $\begin{array}{c}\text { Huangzh } \\
\text { ong } \\
\text { county }\end{array}$ & $\begin{array}{c}\text { Huangyu } \\
\text { an county }\end{array}$ & $\begin{array}{c}\text { Datong } \\
\text { county }\end{array}$ & $\begin{array}{c}\text { Haiyan } \\
\text { county }\end{array}$ \\
\hline $\begin{array}{c}\text { C(Coordination degree) } \\
\text { D(Coordinated }\end{array}$ & 0.499 & 0.499 & 0.496 & 0.499 & 0.471 & 0.389 & 0.488 & 0.487 \\
$\begin{array}{c}\text { development }) \\
\text { RHC(Coordination level })\end{array}$ & 0.693 & 0.265 & 0.358 & 0.285 & 0.324 & 0.233 & 0.251 & 0.393 \\
\hline
\end{tabular}

Combined with figure 1 and table 4 shows the agricultural economic development index of Qinghai Huangshui river basin is higher than that of the eco-environmental quality index, and its coordination degree is 0.685 , and the development degree is 0.543 , QinghaiHuangshui basin belongs to the mild imbalance development of environmental profit and loss model, future development should pay attention to in the pursuit of rapid economic development of agriculture at the same time attaches great importance to the protection and improvement of ecological environment, coordinated development of both synchronous towards a higher level.

\section{Conclusion}

\section{the development of agricultural economy}

Agricultural economy development is highest weights in the influential factors of agricultural labor force, the number of facilities agricultural area and the development of animal husbandry, show that to increase the number of agricultural labor force and expanding facilities agricultural production area and vigorously develop animal husbandry and increase its output value proportion to improve agricultural economic benefits. The agricultural economy development index of Haiyan county overall is low, the highest do not exceed 0.3 , Huangshui river basin in order from high to low is village, ping, about this, taking county, Huangyuan county, necessary, the consistent with 
actual situation. Huangshui river basin, the speed of agricultural economic development faster is village in and about, is the main reason affecting the agricultural economy development high weight of index in this highest total labor resources, taking the sea county.

\section{environmental quality}

It is known that the weight is higher in forest cover, landdesertificationarea and fertilizer use, among which the county with the highest forest coveragerate, reached $48.26 \%$, while in Leducounty and Huangzhong county were $21.52 \%$ and $17.2 \%$ respectively, Haiyancounty is only $11.25 \%$. Forest coverage rate directly affects the quality ofecological environment. Forest coverage rate of Haiyancounty is lowest but the ecological environmental quality index is higher than Huangyuan county. In fertiliser use, it's $12.43 \times 10^{9} \mathrm{t}$ in Ledu county, $5.46 \times 10^{9} \mathrm{t}$ in Datong county, and about $4.56 \times 10^{9}$ in Huangyuan county, $5.58 \times 10^{9} \mathrm{t}$ in Huangzhong county, $10.54 \times 10^{9}$ in Minhe county, $6.77 \times 10^{9}$ in Ping'an county, $7.56 \times 10^{9} \mathrm{t}$ in Huzhu county, and $9.36 \times 10^{9}$ in Huangyuan county, the use of excessive can cause serious pollution to soil and groundwater, caused great stress to the environment, must be improved.

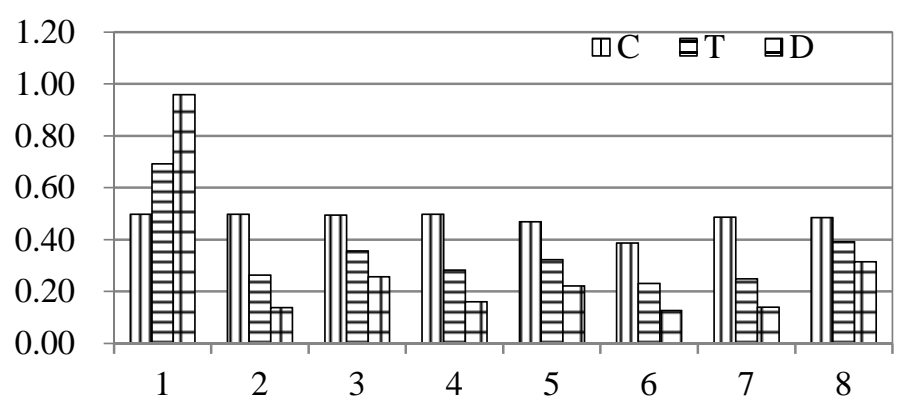

(Note: 1 Ledu county 2 Ping'an county 3 Huzhu county 4 Minhe county5 Huangzhong county 6 Haiyan county 7 Huangyuan county 8 Datong county)

Fig1 The coordination degree, coordination degree and coordinated development of agricultural system and ecosystem in Huangshui River Basin

\section{degree of coordination}

Coordinate degree is used to reflect whether the agricultural economy and ecological environment coordinated development of scale, Huangshui basin of coordination degree are respectively village in Ping'an county was $0.261,0.685$, the Huzhu county, about 0.391and 0.225, this is 0.224 , the sea taking county was 0.313 , Huangyuan county, problems during 0.3930 .251 , show in 2015, the highest degree in agricultural economy and ecological environment coordinate of the village.Haiyancounty is rich in grassland resources, and its agricultural economy depends mainly on the development of animal husbandry. This also makes the abundant grassland resources fully utilized and basically realizes coordinated development.

\section{coordinated development}

In this study, not just confined to research the development of agricultural economy and ecological environment coordinated degree, as can be seen from the above analysis, necessary in the low level of agricultural economy and ecological environment quality index, coordination degree can still achieve 0.393. Village in Ping' an county was $0.265,0.693$, the Huzhu county, about 0.385 0.285 , this is 0.324 , taking sea county was 0.233 , Huangyuan county, problems during 0.3930 .251 , it is enough to prove the degree coordination can't reflect the level of coordination.Therefore, this paper has raised the issue of coordinated development.Can see from the data village in the coordination of the highest levels, that village in the coordinate is relative to other several county high levels of coordination, not only the coordination degree is high, and the agricultural economy and ecological environment of their respective development level is relatively high. 


\section{Coordinate development Suggestions and countermeasures}

The deterioration of ecological environment in Huangshui river basin is the result of the long-term effects of natural and human factors, and the task of ecological environment restoration is urgent and arduous.Due to the severe shortage of water resources in the region, water resources are decreasing in general, and the decrease in recent years is increasing.The existing water resources cannot meet the local ecological demand, and has posed a serious threat to the ecological environment construction and agricultural economic development of Huangshui river basin.Therefore, it is of great significance to put forward the rational utilization of water resources in the Huangshui river basin, which is the most fundamental and effective strategic measure, and also the institutional guarantee for realizing the target of comprehensive watershed management.First, establish water rights system and clarify the initial allocation of water rights.Secondly, we should strengthen the management of afforestation and vegetation resources, strengthen the construction of ecological barrier areas in the Huangshui river basin, restore the vegetation resources, expand the forest coverage and improve the ecological environment.The extension chain of the planting industry is the animal husbandry, which only increases the agricultural circulation and extends the industrial chain to maximize the agricultural benefit.The development of animal husbandry is also an effective way to promote the development of modern agriculture in the oasis area, and to realize the agricultural efficiency and increase the farmers' income.Second, within the planting industry, focus on the development of solar greenhouse vegetables industry, strengthen the sunlight greenhouse refinement and intelligent management, relying on technology unit, cooperation organization, actively develop the order production, promote acquisition sales products classification, maximum limit mining sunlight greenhouse increase production efficiency. Again, in terms of choice of crops can give priority to high value-added economic crops and economic benefit of drought resistance and water saving of high variety, the necessary ecological water use, to achieve economic benefits, social benefits and ecological benefits of the organic unity.

\section{Reference}

[1] LIN Daohui, HEN Xue $\square$ you. Theory advance of environment and economy coordinatingdevelopment[J]. Environmental Pollution \& Control, 002, 4 (2): 120-123.

[2] CHANG A'ping, ENG Wei-gong. Study on index system andquality evaluation of harmonious development for the regionaleconomy and environment[J]. Environmental Science and Man-agement, 009, 10): 176-178.

[3] ZHANG Li. The research of coordinated developmentbetween economy and the environment of Shaanxi Province [D].Xi'an: Northwestern University, 008: 13.

[4] BaiAi-tao, YeDe-ming. Population in northwest arid region-analysis of ecological coupling coordination situation-take Minqincounty in Gansu province as an example [J]. Resource development and market, 2017, (01) : 54-58.

[5] Xiang li. Analysis of agricultural ecological environment and economic coupling in western China [J]. Northern horticulture, 2016, (20) : 203-207.

[6] Zhang Cui-yan, Sun Chuan-guo. Research on the coordination of agricultural ecological environment and economic in Xinjiang Autonomous Region based on coupling model [J]. Journal of Tarim university, 2016, (01) : 49-55.

[7] Song Yong-yong,.Research on the coordinated evolution of agricultural ecological environment and economic coupling in Ningxia[J]. Journal of southern agriculture, 2015, (05) : 922-928. 
[8] Yang Ji-yu. Research on the development of agricultural economy and ecological environment in the Shiyangheriver [J]. Dry area, 2013, (01): 76-83.

[9] Renzhi-yuan, Xuqian. Research on the development of agricultural ecological environment and economic coordination in Shaanxi province[J]. Dry area resources and environment, 2011, (12) : $14-19$. 